\title{
OBITUARY FOR YURI N. CHERNOV 5 NOV 1937 - 1 JAN 2021
}

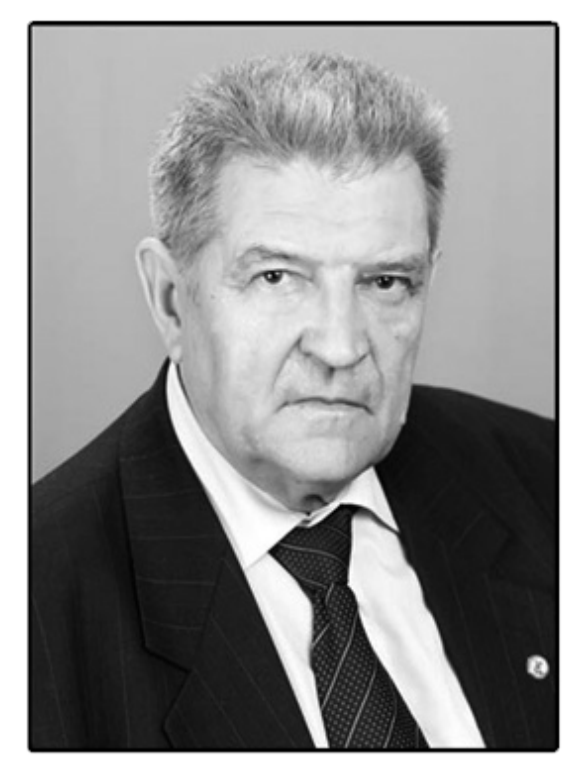

On January 1, 2021, Yuri N. Chernov, Doctor of Sciences (Medicine), Professor, Honored Doctor of the Russian Federation, Academician of the International Human Academy in Aerospace Systems, Corresponding Member of the Russian Academy of Natural Sciences, passed away. Yuri N. Chernov was Honorary Doctor of the State Research and Test Institute of Military Medicine of RF Ministry of Defense, a specialist in the field of clinical pharmacology and aerospace radiobiology, Honorary Professor of Voronezh State Medical University n. a. N.N. Burdenko.

Yuri N. Chernov was born on November 5, 1937 in the city of Voronezh. The desire for research work manifested itself already in school years. He was awarded a Certificate of Merit of the Central Committee of the Komsomol (1954), a bronze medal of a participant in VDNKh (Exhibition of Economic Achievements, 1954) for scientific work in biology.

After graduating from Voronezh Medical Institute in 1961 with a degree in General Medicine, he worked as a general practitioner. In January 1964, he took post-graduate courses at the Department of Pharmacology of Voronezh Medical Institute. In 1971 he defended his thesis for the degree of candidate of medical sciences on the topic "The effect of bee venom (apizartron) and its combination with royal jelly (apilak) on the course and outcome of experimental myocarditis". The work was published in five languages and received recognition from the public at the XXIIIrd International Apimondia Apiculture Congress, Moscow (1971).

From 1971 to 1987, Yuri N. Chernov, working as an assistant, a senior teacher, an associate professor of the Department of Pharmacology, combines research, pedagogical work with organizational and social activities.
From 1973, he was appointed the deputy dean, from 1992 to 2006, Yuri N. Chernov was three times elected the dean of the medical faculty of Voronezh State Medical Academy.

For 33 years, Yuri N. Chernov worked in the dean's office of the largest medical faculty of VSMU n.a. N.N. Burdenko.

As an outstanding organizer and a scholarly man, Yuri Nikolayevich was able to think strategically, and successfully solved assigned tasks proceeding from the knowledge of human psychology, his own life experience and the ability to carry on a constructive conversation.

Fairness and detachment, honesty and openness, insight, self-control - these were the qualities that Yuri $\mathrm{N}$. enjoyed respect and authority among the teaching staff, graduate students, residents and students for. Among them, there was a catch phrase: "Chernov is more than the dean to the medical faculty, not everyone is born as a dean."

In 1980, by order of the Minister of Defense, Yuri N. Chernov was assigned to the State Research Institute of Aviation and Space Medicine (since 1999, the State Research and Test Institute of Military Medicine of the Ministry of Defence). Under the leadership of Academician of the International Academy of Astronautics (IAA) V.V. Antipov, Yuri N. Chernov dealt with the problems of anti-radiation protection of aircraft crews.

In 1987, Yuri N. headed the Department of Clinical Pharmacology, which was first created, with his active participation, at the Voronezh Medical Academy. He headed the Academy until 2011, and then remained an Honorary Professor of the Department of Clinical Pharmacology in Voronezh State Medical University n. a. N.N. Burdenko. Yuri N. was able to support and encourage 
the colleagues, instill confidence in success and motivate employees to move forward due to being a vivid example of the highest degree of professionalism and great diligence, with tireless energy and committed to his work.

Based on the State Research and Test Institute of Aviation and Space Medicine, in the period from 1980 to 1991, he carried out his thesis research, and in 1991 he defended the doctoral thesis. The topic of his research was "Study of biochemical changes in the brain against the background of functional and behavioral manifestations of radiation damage to the central nervous system and the development of means of pharmacological correction of these disorders."

Professor Chernov, a talented scientist-pharmacologist and a toxicologist, always strived to develop new directions of scientific research necessary for solving problems in clinical practice.

Under the leadership of Yuri N., the following scientific studies were carried out: monitor side effects of drugs; pharmacogenetics and environmental pharmacology, clinical pharmacology of drugs for the treatment of diabetes mellitus; arterial hypertension; peptic ulcer of the stomach and duodenum; drug interactions; antimicrobial therapy; pharmacological correction of endothelial dysfunction.

Professor Chernov attached great importance to the problems of pharmacoeconomics and pharmacoepidemiology, including the development of software for calculating the costs of pharmacotherapy in real clinical practice.

Professor Chernov's scientific research comprised not only clinical works but also works on experimental pharmacology including the following problems: a way to optimize the therapy of poisoning with antipsychotic drugs; search for adaptogenic activity of natural compounds; the study using pharmacological analysis of structural and histochemical changes in the cerebral cortex in cerebral syndrome of acute radiation sickness; pharmacological correction of exposure to ultra-lethal doses of ionizing radiation with the subsequent development of new radioprotectors.

The main scientific studies on the basis of the Institute of Aviation and Space Medicine were carried out in the field of radiobiology, and a comprehensive assessment of the operators' health was also developed to ensure a high level of combat effectiveness and prolong the "career longevity" of the Air Force personnel, as well as the principles of effective and safe prescription of drugs for individuals of camera professions.

Professor Chernov is the author of 520 scientific publications, 5 textbooks on clinical pharmacology, 27 textbooks, 6 monographs, 2 chapters of the national guidelines on clinical pharmacology (2009), practical guidelines on aviation and clinical medicine (2011), 42 patents and 5 software systems, registered in the Register of programs of the Russian Federation.
Professor Chernov created a scientific school of clinical pharmacologists. Yuri N. was a thesis director of 32 theses for a candidate degree, 4 theses for a doctor's degree. Professor Chernov's students successfully work in Russia, Commonwealth of Independent States, Europe, the USA and Great Britain.

Yuri N. Chernov, a wonderful teacher and a brilliant speaker, devoted a lot of effort to teaching clinical pharmacology. His bright lectures had always attracted the interest of students, graduate students, clinical residents, doctors of postgraduate training. Professor Chernov participated in the development of curricula in the discipline for medical universities of the country, in the creation of methodological manuals aimed at the formation of a systematic approach to mastering the necessary professional knowledge among graduate students for the effective and safe use of drugs. The presence of outstanding business and personal qualities helped him in solving numerous problems.

For the first time in the Central Black Earth Region, Professor Chernov organized a course of postgraduate training for doctors of clinical pharmacologists. The result of his efforts was the organization of a clinical pharmacology service in the Voronezh and Lipetsk regions, training of doctors, i.e. clinical pharmacologists for medical organizations in Tambov and Belgorod.

For 5 years, Professor Chernov was a member of the Pharmacological Committee of the USSR (1st Commission); a Member of the Board of the Association of Clinical Pharmacologists of Commonwealth of Independent States; Member of the problem commission No.32.02 of the Russian Academy of Medical Sciences "Pharmacology of heart and blood vessels"; Member of the Bureau of the Problem Commission No.32.06 "Clinical Pharmacology" (First Moscow State Medical University n. a. Sechenov); Member of the Thesis Board of VSMU n. a. N.N. Burdenko.

Professor Chernov was also Member of the editorial board of the journals "Experimental and Clinical Pharmacology" (Moscow), "Medicine remedies" (Moscow), the federal annual guidelines "Formulary system".

Professor Chernov made a scientific contribution to the development and strengthening of international relations of pharmacologists of our country with the European scientific community.

From 1997 to 2018, he actively supported scientific contacts with the Institute of Clinical Pharmacology of the Charite Clinic (Germany), where joint studies were carried out to research the role of polymorphic enzymes in the development of various types of cancer and where, under his leadership, the scientific work "Genotyping of drug enzymes metabolism" was executed.

Professor Chernov was a clinical pharmacologist of the highest medical qualification, an honored doctor of Russia, had the title of "Excellent Worker of Public Health". For achievements in space medicine and numerous discoveries, he was awarded a diploma of the Commander-in-Chief of the Air Force, the Order of 
Friendship of Peoples, the Medal of the Air Force Veteran, the Medal n. a. Yu. A. Gagarin, the Order of Merit to the Fatherland, II degree, the medal n. a. G.K. Zhukov, the medal "Veteran of Labor", the merit badge "For Merit to the Voronezh Region". Professor Chernov was also a prize winner of the forum "Golden Fund of the Voronezh Region" in the nomination "Education".
Yuri N. Chernov was a great scientist, a wonderful teacher, a bright personality, a man of great depth and courage. Professor Chernov's high professionalism, wisdom and good-heartedness will always be in the memory of the scientific community, as well as his many students, colleagues and everyone who was happy to know and work with Yuri N.

\section{REST IN PEACE!}

Mikhail V. Vasin - Doctor of Sciences (Medicine), Professor of the Department of Disaster Medicine of the Russian Medical Academy of Continuing Professional Education; Senior Researcher of the Research and Test Center of aerospace and military ergomedicine of the Central Research Institute of the Air Force of the Ministry of Defence (the Russian Federation).

Igor E. Esaulenko - Doctor of Sciences (Medicine), Professor, Academician of the Russian Academy of Natural Sciences; honored worker of higher education of the Russian Federation; Rector of Voronezh State Medical University n. a. N.N. Burdenko.

Vladimir G. Kukes - Doctor of Sciences (Medicine), Professor, Academician of the Russian Academy of Medical Sciences; I.M. Sechenov First Moscow State Medical University.

Vladimir I. Petrov - Doctor of Sciences (Medicine), Professor, Academician of the Russian Academy of Medical Sciences; Chief Clinical Pharmacologist of the Ministry of Health of the Russian Federation, President of Volgograd State Medical University.

Igor B. Ushakov - Doctor of Sciences (Medicine), Professor, Academician of the Russian Academy of Sciences; State Scientific Center of the Russian Federation - Federal Medical Biophysical Center n. a. A.I. Burnazyan, Federal Medical and Biological Agency of Russia. Alexander L. Khokhlov - Doctor of Sciences (Medicine), Professor, Corresponding Member of the Russian Academy of Sciences; Chief clinical pharmacologist of the Yaroslavl region and the Central Federal District of the Russian Federation.

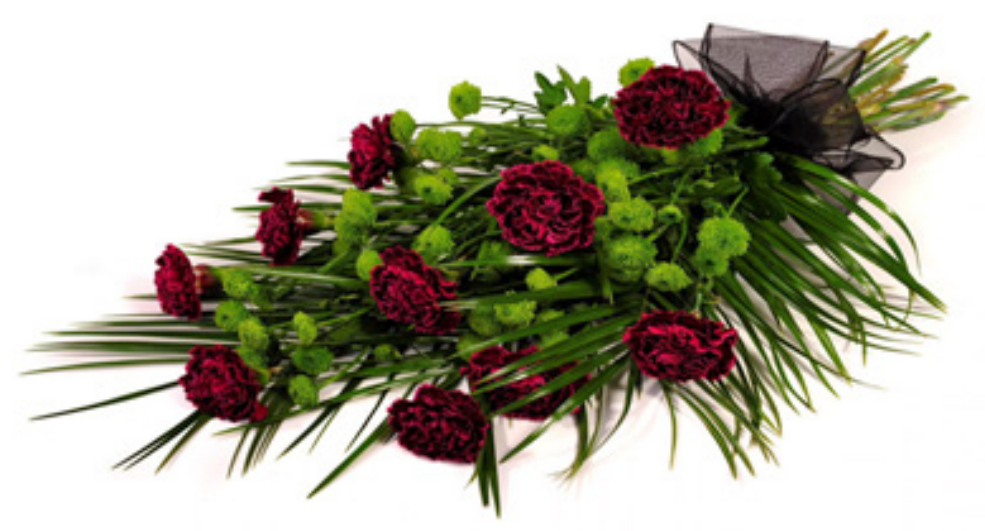

